\title{
Ch. Cotin, Les enigmes de ce temps
}

\section{Cristina Bernanzzoli}

\section{Q OpenEdition}

\section{Journals}

\section{Edizione digitale}

URL: https://journals.openedition.org/studifrancesi/39258

DOI: 10.4000/studifrancesi.39258

ISSN: 2421-5856

\section{Editore}

Rosenberg \& Sellier

\section{Edizione cartacea}

Data di pubblicazione: 1 décembre 2004

Paginazione: $359-360$

ISSN: 0039-2944

\section{Notizia bibliografica digitale}

Cristina Bernanzzoli, «Ch. Cotin, Les enigmes de ce temps», Studi Francesi [Online], 143 (XLVIII | II) |

2004, online dal 30 novembre 2015, consultato il 19 mai 2021. URL: http://journals.openedition.org/ studifrancesi/39258; DOI: https://doi.org/10.4000/studifrancesi.39258

Questo documento è stato generato automaticamente il 19 mai 2021.

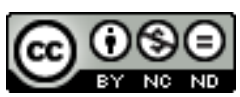

Studi Francesi è distribuita con Licenza Creative Commons Attribuzione - Non commerciale - Non opere derivate 4.0 Internazionale. 


\title{
Ch. Cotin, Les enigmes de ce temps
}

\author{
Cristina Bernanzzoli
}

\section{NOTIZIA}

CH. COTIN, Les enigmes de ce temps, texte établi, présenté et noté par FLORENCE VUILLEUMIERLAURENS, Paris («Société des Belles Lettres, Textes François» 231), 2003, pp. 218.

1 Con la presente edizione l'A. cerca di riabilitare il genere dell'enigma e, con esso, l'«inventore» di questa nuova moda nella prima metà del XVII secolo: l'abbé Cotin, il cui nome è invece spesso associato al fenomeno della «préciosité ridicole».

Data fondamentale nella storia del genere enigmatico è il 1638, anno in cui Chapelain sancisce, in una lettera ad Antoine Godeau, la nascita del gioco dell'enigma presso i salotti mondani dell'epoca, ed in cui vengono pubblicati ben quattro volumi riguardanti tali poemi: tre comprendenti le produzioni di vari autori (tra cui cotin) ed uno riservato unicamente agli enigmi dell'abbé, il Recueil des Enigmes de ce temps, edito presso Antoine de Sommaville e preceduto da un importante «Discours sur les Enigmes».

3 La raccolta, arricchita da nuovi pezzi, oltre che dalla «Letttre à Damis» - in cui l'autore precisa ed affina il suo parere sui soggetto in questione - è ripubblicata otto anni più tardi da Toussaint Quinet col titolo Recueil des Enigmes de ce temps. Première partie. Una seconda e terza parte (riservate ad altri scrittori) verranno aggiunte nel 1655, anno in cui Cotin è ammesso all'Académie Française; risalgono invece al 1659 le Oeuvres mesles contenant énigmes, odes, sonnets et épigrammes (base di questa edizione), in cui gli enigmi, che rappresentano la parte più consistente del libro, sono pure introdotti da una épittre/ dédicace indirizzata alla figlia di Gaston d'Orléans.

4 Ma la fonte più preziosa per l'apprezzamento del genere sarà costituita dalle Oewres galantes (1665) le quali, oltre a fornire un preciso ritratto della micro-società galante che Cotin ben conosceva, daranno prova della sua erudizione e della sua capacità di dissertare su argomenti retorici, e non solo in modo tutt' altro che pedantesco.

5 Al termine di questo necessario excursus, Florence VuILLEUMIER-LAURENS riserva ancora due parti della sua articolata introduzione allo studio della storia e della poetica 
dell'enigma, chiudendo infine la raccolta con un'ampia bibliografia e cinque interessanti annexes, i quali attestano e precisano quanto sopra. 